\title{
PROTEÇÃO AMBIENTAL: MAIS QUE DEVER, CRITÉRIO HERMENÊUTICO
}

Jorge Di Ciero Miranda* Eduardo Rocha Dias**

SUMÁRIO: Introdução; 2 Hermenêutica em Evolução; 3 Enquadramento Jurídico da Defesa do Meio Ambiente; 4 A Hermenêutica Constitucional Transformada pela Defesa Ambiental; 5 Considerações Finais; Referências.

RESUMO: Por intermédio do presente artigo pretende-se identificar de que modo o despertar para preocupações ambientais repercutiu na forma de ver e interpretar o direito. A metodologia exploratória propóe identificar que as tarefas da interpretação constitucional passam necessariamente pela proteção ambiental. O objetivo geral consiste em identificar de que modo a defesa do meio ambiente afeta a hermenêutica constitucional. Os objetivos parciais consistem em reconhecer qual a contribuição da hermenêutica clássica para a estruturação da hermenêutica constitucional, identificar a natureza jurídica do meio ambiente saudável e sua proteção. De posse desses dois elementos, busca-se o terceiro objetivo parcial que consiste em reconhecer de que modo ambos são úteis para a hermenêutica constitucional. Considera-se finalmente que através da utilização dos valores ambientais será possível almejar a expressão plena dos direitos fundamentais, o que faz desses valores componentes inseparáveis das regras de interpretação.

PALAVRAS-CHAVE: Defesa ambiental; Direitos fundamentais; Hermenêutica clássica; Hermenêutica constitucional.

\section{ENVIRONMENTAL PROTECTION IS MORE THAN A DUT Y: THE HERMENEUTIC CRITERION}

\begin{abstract}
Repercussions of environment conscience-raising on the perception and interpretation of law are identified. The exploratory methodology identifies that the tasks of constitutional interpretation necessarily occur through environmental protection. The main aim of the paper is to identify the manner the defense of the environment affects constitutional hermeneutics. Specific aims consist in acknowledging the contribution of classical hermeneutics for the structuring of constitutional hermeneutics, identification of the juridical nature of a healthful

\footnotetext{
Juiz de Direito em Fortaleza (CE); Mestre em Direito pela Universidade de Fortaleza (UNIFOR), Fortaleza (CE), Brasil; E-mail: jorgediciero@hotmail.com Direito Constitucional da Universidade de Fortaleza (UNIFOR), Fortaleza (CE), Brasil.
}

** Doutor em Direito pela Universidade de Lisboa, Portugal; Docente Titular do Programa de Pós-Graduação em
\end{abstract}


environment and its protection. These two factors produced a third aim which consists in acknowledging how both are useful for constitutional hermeneutics. The employment of environmental values may provide the full meaning of fundamental rights, and transforming these values as inseparable components for interpretation rules.

KEY WORDS: Classic hermeneutics; Environmental defense; Constitutional hermeneutics; Fundamental rights.

\section{PROTECCIÓN DEL MEDIO AMBIENTE: SINO QUE EL DEBER, CRITERIO HERMENÉUTICO}

RESUMEN: A través de este artículo se pretende identificar cómo lo despertar a las preocupaciones ambientales refleja en la manera de ver e interpretar la ley. La metodología exploratoria propone identificar las tareas de interpretación constitucional pasan necesariamente por la protección del medio ambiente. El objetivo general es identificar la forma en la protección del medio ambiente afecta a la hermenéutica constitucional. Los objetivos parciales son reconocer la contribución hermenéutica clásica a la estructuración de la hermenéutica constitucional, identificar la naturaleza jurídica de un medio ambiente saludable y su protección. Con estos dos elementos, se busca el tercer objetivo parcial que consiste en reconocer la forma en que ambos son útiles para la hermenéutica constitucional. Por último, se cree que a través de la utilización de los valores ambientales será capaz de aspirar a la plena expresión de los derechos fundamentales, lo que hace que estos valores de los componentes inseparables de las reglas de interpretación.

PALABRAS-CLAVE: La hermenéutica clásica; La hermenéutica constitucional; Los derechos fundamentales; Protección del medio ambiente.

\section{INTRODUÇÃO}

O despertar para as questões ambientais representa salto evolutivo, na medida em que permite ao homem reconhecer-se parte e não proprietário da natureza, forçando-o a abandonar a visão instrumental que preponderou na maior parte dos séculos XIX e XX. Essa preocupação não induz apenas novos mecanismos para interpretar a lei, mas principalmente para compreender as questões fundamentais que estão envolvidas na solução de cada conflito que a norma pretende regular. 
Com o auxílio da hermenêutica, pode-se mitigar o impulso, ou a necessidade, que os intérpretes encontram de servir-se apenas das suas convicções pessoais para a solução dos "casos difíceis". A utilização do argumento de autoridade distancia o julgador da lógica argumentativa e retira da decisão a sindicabilidade que a estrutura racionalmente. A possibilidade de submeter a argumentação a processos hermenêuticos identificáveis dota as decisões judiciais de previsibilidade, sem que isso importe manietar a força criadora inerente ao ato de julgar. Tais padrões são assazes a preservar a autonomia do direito e demonstrar sua coerência e utilidade.

Nesse sentido, pode-se perceber que algumas expressões já lançadas na redação original da Constituição, como dignidade da pessoa humana, desenvolvimento humano e crescimento econômico, ou mesmo a defesa do meio ambiente podem alcançar maior grau de revelação e de concretização. Defendese que os autores clássicos, que despertaram para a necessidade do pensamento hermenêutico, influenciam ainda hoje a interpretação constitucional. Desse modo, um dos objetivos parciais do trabalho consiste em identificar quem seriam os autores estruturantes e de que modo contribuem para a hermenêutica constitucional.

O objetivo geral do artigo é identificar de que modo a previsão constitucional de defesa do meio ambiente afeta a aplicação das normas, com considerações de hermenêutica. Para tanto, a natureza jurídica e o âmbito de extensão das normas de proteção do ambiente natural são tratados também como objetivo específico.

O terceiro objetivo parcial consiste exatamente em identificar de que modo a hermenêutica se relaciona com os dispositivos sobre proteção ambiental de modo a torná-la útil à solução de casos concretos, mesmo que o meio ambiente não esteja diretamente ligado ao conflito.

Espera-se na inclusão permanente da preocupação ambiental como critério hermenêutico diminuir o peso da responsabilidade do julgador nas situações em que a lei se supõe insuficiente e que envolvam direitos fundamentais. Defende-se que nos casos difíceis há sempre um fojo preparado a quem se dispõe a solucioná-los. Essa armadilha deriva não apenas da complexidade que lhe é inerente, mas também da certeza que a solução invariavelmente atrairá a crítica dos que se precipitam ao julgamento açodado. Tais críticas poderiam converter-se em argumento dialético, desde que proviessem daquele que detém conhecimento dos fatos e dos métodos hermenêuticos aplicados. Daí se extrai que a simples exposição dos métodos hermenêuticos já serviria como justificativa do trabalho. 
Em razão da complexidade e abstração do objeto de estudo, o método utilizado é hipotético-dedutivo. Toma-se por pressuposto que os conhecimentos disponíveis sobre o tema não são suficientes para fornecer critério objetivo para solução de questões que desafiam a proteção ambiental. Dessa impossibilidade de oferecer resposta conclusiva e objetiva é que surge o problema. Para tentar explicálo, são formuladas hipóteses que se pretendem falseáveis.

Do ponto de vista da natureza, a pesquisa é aplicada, isto é, tenciona gerar conhecimentos para utilidade prática, dirigidos à solução de problemas específicos. Quanto à abordagem do problema é qualitativa, em virtude da relação dinâmica que se estabelece entre os problemas que se propõe a resolver e a subjetividade do intérprete, que não pode ser traduzida em números. Em relação aos objetivos a pesquisa é exploratória porque visa aproximar o leitor do problema com vistas a construir hipóteses. Por fim, o trabalho serve-se de pesquisa bibliográfica e documental.

A delicada função criadora do juiz oscila entre o Procusto, como metáfora do tirano intelectual intolerante aferrado ao paradigma positivista, e o alternativo, liberal e inconsequente, para quem a lei nada representa e que não hesita na intransigência revelada em seu solipsismo casuístico. Para evitar essas posições extremadas recorrese aos clássicos da hermenêutica que contribuíram para constituir teoria a respeito, conforme se vê a seguir.

\section{HERMENÊUTICA EM EVOLUÇÃO}

$\mathrm{O}$ reconhecimento do papel que a hermenêutica desempenha na aplicação do direito está condicionado à visão e expectativa que se tem dela. Desse modo, expectativa e visão relacionam-se à natureza da hermenêutica. O que é a hermenêutica?

Considerada a arte ou a técnica de extrair o sentido de textos, visando tornálos inteligíveis, liga-se a uma longa e rica tradição. A compreensão de textos religiosos e jurídicos se encontra em sua gênese, tendo contribuído para o desenvolvimento de uma abordagem filosófica e científica do problema da interpretação. O homem, através da evolução da linguagem, incrementou as condições de acumulação de conhecimento, não apenas no aspecto quantitativo, mas também qualitativo, 
conforme o torna complexo. A evolução científica requer criticidade para que o processo dialético possa depurá-la. A linguagem não é apenas o código comum, capaz de ser emitido e percebido pelo destinatário, ela é o próprio limite de apreensão do conteúdo, da compreensão. Na expressão de Lenio Streck "a linguagem, entendida historicamente como uma terceira coisa interposta entre um sujeito e um objeto, recebe o status de condição de possibilidade de todo o processo compreensivo"1.

A hermenêutica é ferramenta útil para revelar e reduzir os efeitos reducionistas da linguagem na transmissão da ciência, efeitos capazes de comprometer a comunicação e sua criticidade. A construção cultural somente se torna perceptível pela linguagem, a hermenêutica a torna a científica. Emilio Betti ${ }^{2}$ discorre sobre a utilidade de adoção de um método para se chegar a uma resposta (interpretação) correta. O italiano chama a atenção, através da semiótica, para a importância da construção de sentido nos textos verbais e não-verbais, de modo a evitar que a interpretação se converta em visão incapaz de aferir a realidade social e psicológica - ambas mais amplas que o texto.

Nesse sentido, destaca-se a necessidade de aproximar os mundos envolvidos na interpretação: o ecológico e o econômico. O biológico como sustentáculo vital para a espécie humana, o econômico pleno de representações que se traduzem em custo e valor. Na busca de sentido para o texto vem a necessidade de reconhecer semelhanças e divergências para que as duas visões complementares tornem claro o que é oculto e consigam traduzir o seu sentido, nisso consiste sua atualização. Para Palmer $^{3}$ a hermenêutica possui três significados: dizer/anunciar, explicar e traduzir.

Dos seus postulados pode-se inferir que a hermenêutica é a transferência de mensagem, de um mundo para outro, é a mediação entre eles, a ponte entre o presente e o passado, o divino e o humano, ou quaisquer outros planos ou domínios que se tocam no objeto de estudo. Conforme a proposta em estudo, o mundo ecológico, ou melhor, a consideração biológica do homem, é realidade inafastável de qualquer outra percepção científica. Fundar essa visão de mundo instaura a epistemologia ambiental que exige interpretação dos fatos que lhe seja consentânea.

Para melhor compreensão da proposta há que se retroceder às seis

\footnotetext{
${ }^{1}$ STRECK, Lenio Luiz. Superando os Diversos Tipos de Positivismo: Porque Hermenêutica é Applicatio? Nomos - Revista do Programa de Pós-Graduação em Direito da UFC. Fortaleza: Editora Universitária, 2014, p. 275-298, p. 276

2 BETTI, Emilio. Teoria Geral da Interpretação Jurídica. 2007.

3 PALMER, Richard E. Hermenêutica. Trad. Maria Luísa Ribeiro Ferreira. Edições v.70, 1999.
} 
concepções sobre hermenêutica, utilizadas por Palmer ${ }^{4}$ : teoria de exegese bíblica e a teoria filológica. Existe também a visão como ciência de compreensão da linguagem, ou base metodológica das ciências do espírito. Pode ser também sistema de transformação iconoclástico (de destruição dos ícones) ou instrumento para referenciar a generalidade da norma no caso concreto. Por certo que o caminho a percorrer no processo hemenêutico já revela, ou pelo menos sinaliza, o destino que se almeja, mas é na forma de trilhá-lo que o intérprete pontua suas prioridades. A viabilidade ambiental é "destino" a alcançar, estabelecer o grau de comprometimento que outros valores e princípios precisarão sofrer em função dela é da hermenêutica.

O "dasein" de Heidegger" alerta para o assimilável através da experiência histórica humana que já produziu a esterilidade e o término das funções ambientais em diversos lugares do mundo, esses processos históricos negligenciaram a degradação que o ser humano promoveu. Gadamer ${ }^{6}$ chama a atenção sobre as falhas do método de alcançar a compreensão, na sua extensão mais ampla, por meio da experiência, pode-se deduzir a insuficiência dos esforços cognitivos que fundamentam a inteligência compreensiva que nem sempre dispensam a exigência de uma incursão teórica de natureza epistemológica para repousar na própria experiência mundana, na realidade histórica, na experiência, no tempo, na tradição.

Por esse motivo que tratar de decisões judiciais de maneira racional não importa exclusividade do positivismo descritivo. A aplicação de precedentes de maneira adequada, exige, antes de mais nada, capacidade para reconhecê-los (enquanto precedentes vinculantes) e serenidade. Ambas qualidades são necessárias às ciências do espírito, que não almejam a certeza pretendida pelas ciências da natureza, em lugar disso, prefere a compreensão das suas limitações, próprias das ciências deontológicas.

O que se pode extrair é que as questões carentes de tratamento hermenêutico não se separam do dever de fundamentação das decisões judiciais, são uma coisa só. Pode-se dizer que a legitimidade da jurisdição está subordinada ao correto estabelecimento de pontes entre o dever ser da norma e o caso concreto. Conforme se defende, o "dever ser" da norma traz implícito o valor ambiente saudável, como condição de realização do direito.

Habermas e Apel estruturam a legitimação da produção da norma na Teoria da Ação Comunicativa e na Ética do Discurso. Baseiam-se em dois princípios que

${ }_{4}^{4}$ PALMER, Richard E., op. cit., 1999.

${ }^{5}$ HEIDEGGER, Martin. Ser e Tempo. Petrópolis: Vozes, 1995, p. 96.

${ }^{6}$ GADAMER, Hans-Georg. Verdade e método I. vol. 7. Trad. Flávio Paulo Meurer. 1997. 
devem permear qualquer discurso que tenha a pretensão de validade: o Princípio D (do Discurso) e Princípio U (da Universalização) ${ }^{7}$.

Desse modo, Jürgen Habermas ${ }^{8}$ funda a legitimidade do direito na linguagem e na razão comunicativa, capacitam-no para aplicação e o tornam apto para a ação. O discurso universal não se converte em fonte de normas de ação, mas em condição para se alcançar o consenso na elaboração (concretização) da norma. A vontade dos cidadãos encontra ambiente propício para ser expressa na formação discursiva da opinião, que por sua vez legitima o direito.

A perspectiva de Habermas parte da compreensão do direito como forma que estabiliza as expectativas sociais de comportamento e do princípio do discurso como critério para aferir a legitimidade das normas de ação em geral. Com fundamento em tais premissas, o autor defende que é possível introduzir, in abstracto, categorias de direitos que originam o próprio código jurídico e que determinam o status das pessoas. Entre tais direitos, ele menciona direitos fundamentais a condições de vida garantidas social, técnica e ecologicamente, na medida em que se faça necessário para o aproveitamento em igualdade de condições dos demais direitos. A garantia de condições de vida, inclusive no que diz respeito à ecologia, constitui, portanto, o pressuposto das demais categorias de direitos.

Conforme Emilio Betti ${ }^{9}$ sugere, para Dilthey é possível adotar atitude de compreensão interior que se diferencie de uma explicação dos fenômenos. Diferentemente do que acontece nas ciências da natureza, a compreensão é reservada ao mundo histórico-social. Não se persegue a mera explicação dos fenômenos, como acontece naquela. A compreensão advém da experiência psicológica, como fenômeno de impressão do espírito. A experiência imediata é vivida na qualidade de realidade unitária, é o meio que permite a apreensão do ecológico como realidade que circunda a relação histórica do homem com o local onde há de ser aplicada a norma.

Pode-se dizer que a hermenêutica proporciona destaque para o meio ambiente como aspecto estruturante do direito, na medida em que torna-se imprescindível para a existência humana. Desvela-se em Heidegger ${ }^{10} \mathrm{o}$ imperativo de percepção do mundo que só é capaz de ser alcançado por intermédio da

\footnotetext{
COELHO, André. Introdução à ética do discurso. 2014.

${ }^{8}$ HABERMAS, Jürgen. Direito e democracia: entre facticidade e validade. Tempo brasileiro, 2003.

9 BETTI, Emílio; BLEICHER, J. A hermenêutica como metodologia geral das Geisteswissenschaften. Hermenêutica contemporânea, 1992.

${ }^{10}$ HEIDEGGER, Martin. Ser e Tempo. Petrópolis: Vozes, 1995.
} 
hermenêutica e que consiste em reconhecer o que se mostra, sem esquecer daquilo que não se deixa ver. Conforme exposto se deduz que a relação necessária de todo o ordenamento com o meio ambiente poderia decorrer tão somente da noção de que todos os produtos que o ser humano consome, de algum modo tiveram sua origem na natureza, independente dos estágios de transformação e beneficiamento pelos quais passou.

Para as ciências do espírito ("Geisteswissenschaften"), como é o caso do Direito, Dilthey enfatiza a importância da historicidade como forma de constituição compreensiva do homem em relação ao mundo que o cerca. Há, portanto, um mundo construído historicamente por realidades psíquicas individuais.

Surge, desse modo, a necessidade de compatibilizar a prescrição axiológica ambiental, com as teorias do direito. Na Teoria Pura do Direito, Kelsen ${ }^{11}$ faz do jurídico o centro de interesse do Direito, sua pureza metodológica enseja a identificação da norma jurídica como objeto exclusivo da ciência jurídica, repelindo o fato social e o valor. Para dar coerência ao ordenamento jurídico estruturado hierarquicamente, foi obrigado a conceber a norma hipotética fundamental no ápice de sua pirâmide.

Conforme ele próprio categorizava, o Direito era uma "ciência do espírito" e a pretensão dos seus estudos eram "objetividade e exatidão". Por certo, os que buscarem em Kelsen uma fórmula matemática que permita extrair um único resultado correto quando da aplicação da norma, restarão frustrados. Ele jamais pretendeu "uma valoração - uma apreciação livremente axiológica do conteúdo de uma ordem jurídica determinada" ${ }^{2}$, demonstrando com isso o distanciamento que pretende imprimir entre valor e norma, evitando incursionar nos motivos que ensejam a inclusão dos seus conteúdos.

Por meio da teoria de Kelsen desperta-se para a dificuldade de criar jurisprudência coerente, permitir que ela desempenhe sua função criadora sem colocar em risco a integridade do ordenamento. A hermenêutica se acopla à pretensão de preservar a integridade do ordenamento jurídico, sem comprometer a capacidade de solução do caso concreto. Ela propõe soluções adaptadas, no sentido de promover a construção de uma teoria normativa que critique e explique "como" e "o que" fazer. Essa percepção trouxe para o centro das discussões a importância

\footnotetext{
${ }^{11}$ KELSEN, Hans. Teoria Pura do Direito. Trad. João Baptista Machado. 7. ed. São Paulo: Martins Fontes, 2006.

${ }^{12}$ PERTENCE, José Paulo Sepúlveda. Atualidade do Pensamento de Kelsen. In: TEIXEIRA, Sálvio de Figueiredo (Coord.). Estudos em Homenagem ao Ministro Adhemar Ferreira Maciel. São Paulo: Saraiva, 2001, p. 463-478, p. 464.
} 
do método para a hermenêutica, principalmente quando se toma por premissa que as emoções e o inconsciente influem nas decisões.

Até o momento da descoberta das respostas pode-se buscar explicações causais, no âmbito jurídico o universo investigado é necessariamente normado, com proposições anteriores e conhecidas. No momento da justificação, para decidir qual das normas usar ou como aplicá-las, é que surge a necessidade de critérios, capazes de reduzir a força ideológica do julgador.

Para tanto, ao se deparar com a questão posta para análise, o intérprete formata e estrutura as questões incidentes de modo a permitir que se intua a resposta, gera campo propício à concretização da norma. Para que a defesa do meio ambiente seja preocupação hermenêutica constante há que se perquirir de que modo ingressa no ordenamento, qual é o seu enquadramento jurídico, avançando na direção de reduzir a possibilidade de decisionismo e promover solução que não fique adstrita à semântica da palavra como agora se faz.

\section{ENQUADRAMENTO JURÍDICO DA DEFESA DO MEIO AMBIENTE}

Poucas questões em direito surgiram com tamanha amplitude e concepções tão heterogêneas carregadas de ideologia quanto a relação entre os seres humanos e seu meio ambiente. A pré-compreensão ambiental evita que o intérprete caia no subjetivismo e no decisionismo, auxilia-o na rejeição da resposta empírica descompromissada com a coerência.

Quer-se com isso dizer que a relevância do meio ambiente para a subsistência e viabilidade humana não depende apenas da realidade biológica, mas também, ou principalmente, da percepção que os indivíduos cultivam, enquanto unidades psicofísicas vivas. Depende igualmente da capacidade de articular a realidade singular ao histórico-social, de observar como essas forças agem reciprocamente.

Após lembrar autores como James Lovelock, Fritjof Capra, Luc Ferry, François Ost, Christopher Stone, Michel Serres, que fundamentam o reconhecimento da natureza como realidade biológica inseparável da existência humana, Ariel Gomes ${ }^{13}$ chama atenção para a teia de relações vitais que se estabelece entre as espécies e o comprometimento da forma de vida como se conhece quando essa teia precisa

\footnotetext{
${ }^{13}$ GOMES, A. K. Direito Ambiental: Natureza como um Bem da Humanidade ou como Sujeito de Direitos? Cam-
} po Jurídico, v. 1, n. 2, p. 95-124, 2013, p. 115. 
estabilizar-se em outros patamares. Como exemplo, pode-se mencionar que o aumento da concentração de nitrogênio, amônia e enxofre, resultante do processo antrópico, enseja o surgimento de novos organismos, ou adaptações que tornam inviáveis a vida como hoje se conhece.

Não seria demais dizer que a relevância ambiental se presume da relação de causalidade natural e que por esse motivo prescindiria da hermenêutica para ser admitida. No entanto, a noção de sustentabilidade e seus contornos importam necessária e complexa interpretação de norma para traduzir forma de organização social que reproduza a necessidade de mecanismos que evitem a degradação ambiental. A organização econômica deve ser de tal ordem que evite comprometer a capacidade de renovação dos recursos naturais, mas que se preocupe em manter a cautela de não tornar os recursos naturais inexpugnáveis, a ponto de retirar o homem do centro do ordenamento nacional, conforme a Constituição brasileira define, quando trata do meio ambiente.

$\mathrm{Na}$ síntese de Carvalho ${ }^{14}$, o meio ambiente assume a condição e o status de bem jurídico com a criação do Estado ecológico ou Estado ambiental. Ao mesmo tempo Sarlet ${ }^{15}$ prefere reconhecer o ambiente ecologicamente equilibrado como direito fundamental, de observância compulsória no Estado que se quer de Direito, cuja eficácia pode ser buscada no âmbito constitucional.

Portanto, a primeira conclusão sobre o meio ambiente o identifica como realidade vital, biológica, indispensável à sobrevivência humana, ou na expressão que Carla Gomes ${ }^{16}$ extrai de Seewald ${ }^{17}$ "proteger o ambiente é salvaguardar a integridade dos pressupostos que integram o "contexto vivencial dos seres humanos"'. Se indispensável à vida, o meio ambiente preservado deve ser tido por bem jurídico, cuja definição e limite é desafio posto ao hermeneuta, deve ser construído no caso concreto de acordo com os fatores em transformação conforme Belchior e Matias ${ }^{18}$ destacam. No entanto, a dimensão subjetiva do meio ambiente ressoa insuficiente para Carla Amado Gomes, conforme deixa claro quando comenta a Constituição Portuguesa:

\footnotetext{
${ }^{14}$ CARVALHO, Délton Winter de. Dano Ambiental Futuro: A Responsabilidade Civil pelo Risco Ambiental. São Paulo: Forense Universitária, 2008.

${ }^{15}$ SARLET, Ingo Wolfgang. Dignidade da Pessoa Humana e Direitos Fundamentais na Constituição de 1988. Porto Alegre: Livraria do Advogado, 2001.

${ }^{16}$ GOMES, Carla Amado. Risco e modificação do acto autorizativo concretizador de deveres de protecção do ambiente. Faculdade de Direito da Universidade de Lisboa, 2007, p. 57.

${ }^{17}$ SEEWALD, O. Die Bedeutung der Gesundheit im Umweltrecht, in N+R, 1988/4, pp. 161 segs.

${ }^{18}$ BELCHIOR, Germana Parente Neiva; MATIAS, João Luis Nogueira. Propriedade e meio ambiente: uma relação jurídica complexa. Fortaleza: ESMEC, 2011, p. 11. Disponível em: <www.portais.tjce.jus.br/esmec/wp-content/uploads/2011/08/artigo-3.pdf > . Acesso em: 08 jun. 2015.
} 
A sedução provocada pela dimensão subjectiva avançada no artigo $66^{\circ} / 1,1^{\text {a }}$ parte, da Constituição, afigurou-se menos eficaz para promover a alteração comportamental que o Direito do Ambiente demanda. Conceder um "direito" e estabelecer a responsabilidade primacial das entidades públicas no tocante à protecção ambiental pareceu-nos um passo seguro no sentido da desmobilização dos cidadãos para tal desígnio, apanhados na letargia do Estado providência e confiantes na assunção do protagonismo sempre por terceiros $^{19}$.

No mesmo turno, o meio ambiente deve ser reconhecido como direito fundamental de terceira geração. Convém destacar que, para Fernanda Medeiros, "existe uma dupla perspectiva quando ao conteúdo dos direitos fundamentais, os quais podem ser considerados tanto direitos subjetivos individuais como elementos objetivos fundamentais da comunidade" ${ }^{20}$.

O meio ambiente aparece na Constituição brasileira quando ela se reporta à função social da propriedade (artigo $5^{\circ}$, XXII e XXIII), na distribuição de competência material e administrativa dos entes federativos (artigos 23 e 24). No Título VII, que trata da Ordem Econômica e Financeira, a preocupação com meio ambiente aparece em dois momentos: no Capítulo I, que trata dos Princípios Gerais da atividade econômica (artigo 170), bem como ocupa todo o Capítulo VI, "Do Meio Ambiente" (artigos 225 e seguintes).

Conforme faz ver Canotilho ${ }^{21}$, há direito fundamental ao meio ambiente ecologicamente equilibrado e os desafios ambientais crescentes demandam transformação urgente da atuação do Estado. Apesar da Constituição brasileira não utilizar a expressão sustentável ou sustentabilidade, o conceito decorre do próprio sistema que induz à necessidade de compatibilidade entre o econômico com a defesa do meio ambiente (artigo $170 \mathrm{CF} / 88$ ), permitindo destacar a relevância jurídica da proteção ambiental e reconhecer a exigibilidade de sua implementação pela via judicial.

Talvez seja mais rigoroso, no contexto conceptual do direito português, falar de um núcleo essencial de um direito fundamental ao ambiente e à qualidade de vida. Este núcleo essencial pressupõe,

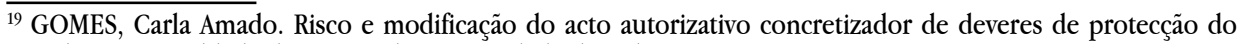
ambiente. Faculdade de Direito da Universidade de Lisboa, 2007, p. 8.

${ }^{20}$ MEDEIROS, Fernanda Luiza Fontoura de. Meio Ambiente: Direito e Dever Fundamental. Porto Alegre: Livraria do Advogado, 2004, p. 85.

${ }^{21}$ CANOTILHO, José Joaquim Gomes. O Princípio da sustentabilidade como Princípio estruturante do Direito Constitucional. Tékhne - Revista de Estudos Politécnicos, 2010. Disponível em: <http://www.scielo.mec.pt/ scielo.php?pid=S1645-99112010000100002\&script $=$ sci_arttext\&tlng $=\mathrm{en}>$. Acesso em: 08 jun. 2015.
} 
desde logo, a procura do nível mais adequado de acção, ou seja, que a execução das medidas de política do ambiente tenha em consideração o nível mais adequado de acção, seja ele de âmbito internacional, nacional, regional, local ou sectorial ${ }^{22}$.

No que se refere ao direito ao meio ambiente ecologicamente equilibrado como sendo de terceira geração, Ferreira Filho ${ }^{23}$ destaca que é o mais elaborado entre eles, porque assegurado à pessoa humana e garantido pelo Poder Público. Constitui-se direito fundamental, previsto na Constituição brasileira de 1988. Não pode ser confundido com direito individual por não ter natureza garantística de uso exclusivo, nem prestacional para que seja admitido como direito social, embora pressuponha atuação do Poder Público, não é um direito oponível ao Estado ou à coletividade, é um convite inescusável de construção conjunta.

Sobre o reconhecimento da relevância de direitos de terceira dimensão ao rol dos direitos individuais (primeira dimensão) e sociais (segunda dimensão), deveu-se à insuficiência ordenadora do Estado Liberal de Direito e promovedora do Estado Social de Direito, que passava a demandar uma transformação a partir da previsão normativa no Estado Democrático de Direito. Para Lenio Streck, "os textos constitucionais passam a explicitar as possibilidades para o resgate das promessas incumpridas da modernidade, questão que assume relevância ímpar em países de modernidade tardia como o Brasil, onde o welfare state não passou de um simulacro" ${ }^{24}$.

Em matéria ambiental, conforme leciona Canotilho ${ }^{25}$, a expressão substancialista reconhece a esse ramo do direito a função de ordenador ou regulador das relações do homem com o seu meio, infiltra-se em outros domínios, público e privado, horizontaliza-se, atrai para o Judiciário a possibilidade de interferir nos seus conflitos. Essa interferência não se dá de modo aleatório, existe um fundamento de ordem material que é o reconhecimento de que se trata de um direito fundamental, transindividual de terceira geração, concebido no modelo brasileiro onde vige o princípio da inafastabilidade que consiste na vedação à exclusão da apreciação do Poder Judiciário de lesão ou ameaça a direito (CF/88, artigo 50 XXXV).

\footnotetext{
${ }^{22}$ CANOTILHO, José Joaquim Gomes, op. cit., 2010, p. 14.

${ }^{23}$ FERREIRA FILHO, Manoel Gonçalves. Direitos humanos fundamentais. São Paulo: Saraiva, 1988.

${ }^{24}$ STRECK, Lenio Luiz. Superando os Diversos Tipos de Positivismo: Porque Hermenêutica é Applicatio? Nomos - Revista do Programa de Pós-Graduação em Direito da UFC, 2014, p. 275-298, p. 276.

${ }^{25}$ CANOTILHO, José Joaquim Gomes. Protecção do Ambiente e Direito de Propriedade. Coimbra: Coimbra Editora, 1995.
} 
Observa-se que essa expressão complexa do direito ao ambiente não se distancia do entendimento do STF conforme se vê na decisão proferida na Medida Cautelar na Ação Direta de Inconstitucionalidade $n^{0} 3540$, de 03 de fevereiro de 2006. O Ministro relator Celso Mello trouxe sínteses relevantes: 1) A preservação da integridade do meio ambiente é um direito (artigo 225), metaindividual, de terceira geração, que consagra o postulado da solidariedade; 2) A criação de espaços territoriais especialmente protegidos e a intervenção judicial justificam-se pela necessidade de impedir transgressão ao direito ambiental e a irrupção de conflitos intergeracionais (cf. artigo 225, $\S 1^{\circ}$, III); 3) A alteração e supressão do regime jurídico dos espaços territoriais estão sujeitos ao princípio constitucional da reserva de lei.

Cabe, porém ressalva quanto à terceira conclusão. Ela não pretende significar que os atos próprios da administração pública que tornam possível a intervenção do homem no espaço natural seriam irreversíveis, mesmo diante da pretensão de lhes conferir estabilidade. Eles não se cristalizam, conforme destaca Filipa Calvão, porque pende, seja a ameaça de revogação, "seja a ameaça de outro tipo de acto susceptível de afectar a posição jurídica" ${ }^{26}$ decorrente do quadro de incerteza que o princípio da precaução enseja em matéria ambiental, conferindo precariedade permanente aos atos que lhe digam respeito.

O acórdão proferido na ADIn 3540 do STF demonstra também o reconhecimento da preservação da integridade ambiental como direito de terceira geração como se vê de parte da sua ementa:

MEIO AMBIENTE - DIREITO À PRESERVAÇÃO DE SUA INTEGRIDADE (CF, ART. 225) - PRERROGATIVA QUALIFICADA POR SEU CARÁTER DE METAINDIVIDUALIDADE - DIREITO DE TERCEIRA GERAÇÃO (OU DE NOVÍSSIMA DIMENSÃO) QUE CONSAGRA O POSTULADO DA SOLIDARIEDADE - NECESSIDADE DE IMPEDIR QUE A TRANSGRESSÃO A ESSE DIREITO FAÇA IRROMPER, NO SEIO DA COLETIVIDADE, CONFLITOS INTERGENERACIONAIS - ESPAÇOS TERRITORIAIS ESPECIALMENTE PROTEGIDOS (CF, ART. 225, $\S 1^{\circ}$, III) - ALTERAÇÃO E SUPRESSÃO DO REGIME JURÍDICO A ELES PERTINENTE - MEDIDAS SUJEITAS AO PRINCÍPIO CONSTITUCIONAL DA RESERVA DE LEI.

A Constituição brasileira dispõe, no artigo 225, que "a defesa e preservação do meio ambiente ecologicamente equilibrado" é dever de todos. Estão incluídos

${ }^{26}$ CALVÃO, Filipa Urbano. Os actos precários e os actos provisórios no Direito Administrativo. Porto: 1998, p. 155. 
na palavra todos, o Poder Público e a coletividade. A leitura da Constituição permite deduzir postura antropocêntrica, que decorre do binômio direito e dever. A relação homem e natureza se faz jurídica e não apenas natural, instaura deontologia própria daqueles que se elegem proprietários, legitima-os para exercer seu papel definido a partir de visão racionalizada que se distancia do biológico. A redação constitucional coloca o homem para além da possibilidade de fruição simbiótica com a natureza, instaura nele o dever de protegê-la, como atividade própria de quem deve concorrer para preservar seus processos conforme sua seleção.

O direito ambiental é permeável a todos os demais ramos, a influência que a proteção ambiental exerce na aplicação das normas não importa na simples inclusão de mais um objeto de estudo, não há acomodação de saberes distintos, mas sim a ampliação da esfera de atuação dos elementos capazes de garantir nível adequado de proteção ao meio ambiente.

Pode-se sustentar que o despertar da necessidade do meio ambiente equilibrado e adequado à sadia qualidade de vida faz emergir relação reflexiva, daí decorrendo sua complexidade e caráter hermenêutico. Nos dizeres de Enrique Leff ${ }^{27}$, a complexidade ambiental "gera o inédito no encontro de outridades, enlaçamento de diferenças, complexidade de seres e diversificação de identidades".

A imposição da preservação ambiental provoca transformações estruturais e qualitativas nos demais ramos do direito. Por vezes os funcionaliza, noutras os subordina, mas em nenhuma hipótese os exclui. Esse dever torna insuficiente a racionalidade jurídica clássica para a interpretação do direito, a segurança do dogmatismo cede espaço ao avanço da ciência na descoberta da relevância de espaços naturais que passam a merecer tratamento diferenciado.

O questionamento que surge da preservação ambiental como dever é exatamente se a humanidade poderia renunciar a ele. Ou ainda, se a ausência de previsão constitucional para proteção ambiental seria o suficiente para excluir o destinatário dessa obrigação. O dever de preservação decorreria de alguma norma positivada?

Em resposta, Baracho Júnior contribui quando distingue a vontade geral em Rousseau: "A vontade geral, em oposição à vontade de todos, é sempre uma vontade reta, tendente sempre à utilidade pública. A vontade de todos seria um fato político,

${ }^{27}$ LEFF, Enrique. Pensar a complexidade ambiental. In: LEFF, Enrique (Coord.). A complexidade ambiental. São Paulo: Cortez, 2003, p. 15-64. 
ao passo que a vontade geral seria um fenômeno moral"28 (grifo no original). A vontade que nos contratualistas tinha acepções lógica, jurídica e teleológica, alcança em Rousseau uma acepção moral ${ }^{29}$.

Quando Bobbio ${ }^{30}$ interpreta o Leviathan de Hobbes conclui que a "lei natural não prescreve ações boas por si mesmas, mas ações boas em relação a um determinado fim, que é a paz" ${ }^{\prime 1}$. O Estado seria, portanto, o meio eficaz para alcançar a paz e conservar o fim supremo definido pela lei natural que é a conservação da vida.

Para o contratualista Hobbes o Estado só se justifica na medida em que se revela apto a realizar o bem pelo qual os indivíduos alienaram parte de sua liberdade: a vida. Toma-se aqui como pressuposto vital a viabilidade orgânica, que só seria viável na presença de meio ambiente equilibrado e protegido. Desse modo, não haveria como deixar de reconhecer o dever a todos impostos de preservar a natureza ainda que essa previsão não estivesse positivada.

O objetivo de tornar efetivo o direito de todos ao meio ambiente ecologicamente equilibrado é tido por Luís Paulo Sirvinskas ${ }^{32}$ como princípio matriz contido no caput do artigo 225 da Constituição Federal. A tutela ambiental é uma obrigação dos Estados que se comprometeram a produzir uma legislação ambiental eficaz, conforme o Princípio 11 da Conferência das Nações Unidas sobre o Meio Ambiente, realizada no Rio de Janeiro em 1992.

Pode-se tomar como síntese que o meio ambiente saudável e equilibrado é direito fundamental de terceira geração, mas é também dever inescusável, a todos impostos. Esse direito não é exercitado com exclusividade e, portanto, não deve ser tomado como individual, nem exige prestação específica do Estado o que o desconstitui como direito social. Não pode ser excluído por escolha política porque é também condição de viabilidade biológica, razão de ser da escolha moral de constituir Estado conforme teoria contratualista de edificar a paz, que nada mais é do que alcançar o fim supremo colocado pela lei natural: conservar a vida.

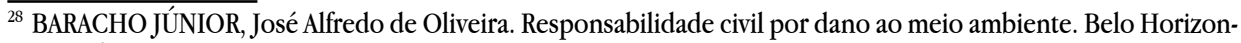
te: Del Rey, 2000, p. 33.

${ }^{29}$ JOUVENEL, Bertrand de. Essai sur la politique de Rousseau. Berlin-Dahlem: Otto-Suhr-Institut, 1965.

${ }^{30}$ BOBBIO, Norberto. Thomas Hobbes. México: Fondo de Cultura Económica, 1992, p. 107.

${ }^{31}$ BARACHO JÚNIOR, José Alfredo de Oliveira. op. cit., 2000, p. 30.

${ }^{32}$ SIRVINSKAS, Luís Paulo. Política nacional do meio ambiente (Lei ${ }^{\circ} 6.938$, de 31 de agosto de 1981). As leis federais mais importantes de proteção ao meio ambiente comentadas. MORAES, Rodrigo Jorge; AZEVÊDO, Mariangela Garcia de Lacerda; DELMANTO, Fabio Machado de Almeida (Coord.). Rio de Janeiro: Renovar, 2005, p. 91-93.
} 
A complexidade que envolve a natureza jurídica do meio ambiente saudável e equilibrado tem repercussões na hermenêutica constitucional, que por sua vez ainda é influenciada pelos mecanismos da hermenêutica clássica que labora para tecer a malha do tecido social conforme se verá a seguir.

\section{A HERMENÊUTICA CONSTITUCIONAL TRANSFORMADA PELA DEFESA AM- BIENTAL}

Diversamente do que possa parecer, a possibilidade de atrair para a dignidade da função, o fundamento da decisão em um caso difícil, naquilo que é reservado à discricionariedade do julgador, transformando argumento racional em argumento de autoridade, é fardo para os que laboram com correção e predisposição para o acerto.

Para ilustrar essa ideia vem a calhar figura lendária. "Procusto é símbolo do mal que assola (e domina) o imaginário dos magistrados atualmente, cristalizando a intolerância e o descaso com as ideias e expectativas alheias, criando um quadro de verdadeira tirania intelectual" ${ }^{\prime 3}$. Ele se torna escravo e vítima do modelo que criou, seu regozijo residia exatamente no desajuste da cama que oferecia aos hóspedes. A partir da impossibilidade de conformação ao molde é que Procusto se erigia à condição de ditar o destino de suas vítimas, invariavelmente condenadas à morte para atender a um padrão estéril.

A nova ordem proposta pela Constituição Federal de 1988 incorpora valores por meio dos princípios constitucionais. Os princípios, como mandados de otimização, são desafiados em conflitos entre direitos individuais e os de concepção solidária. A relativização do direito de propriedade é adotada pelo STF conforme se vê no Acórdão proferido na Ação Direta de Inconstitucionalidade no 2213 , sempre condicionando a supressão ao direito de indenização:

O direito de propriedade não se reveste de caráter absoluto, eis que, sobre ele, pesa grave hipoteca social, a significar que, descumprida a função social que lhe é inerente (CF, art. 5º, XXIII), legitimar-se-á a intervenção estatal na esfera dominial privada, observados, contudo, para esse efeito, os limites, as formas e os procedimentos fixados na própria Constituição da República. - O acesso à terra, a solução dos

${ }_{33}^{3}$ BARRETO, R. M. Do Leito de Procusto à discricionariedade judicial: as implicações do solipsismo filosófico para o direito e sua superação pela hermenêutica jurídica. Prisma Jurídico, v. 10, n. 2, p. 445-470, 2011, p. 446. 
conflitos sociais, o aproveitamento racional e adequado do imóvel rural, a utilização apropriada dos recursos naturais disponíveis e a preservação do meio ambiente constituem elementos de realização da função social da propriedade. A desapropriação, nesse contexto - enquanto sanção constitucional imponível ao descumprimento da função social da propriedade - reflete importante instrumento destinado a dar consequência aos compromissos assumidos pelo Estado na ordem econômica e social. (Acórdão n ${ }^{\circ} 2213$ de Tribunal Pleno S. T. F. de 23 de abril de 2004. Relator: Min. Celso de Mello)

Diante da colisão, o juiz, no desempenho de sua função decisória, vê-se diante do desafio de se desvencilhar da obediência irrestrita ao direito positivado, ainda que injusto. Nesse caso pode buscar, com auxílio da hermenêutica interpretar conforme os valores e postulados que estruturam o ordenamento; ou insurgir-se à lei, curvando-se aos fatos e agindo conforme sua convicção de acerto ou de "Justiça"; o que representaria distanciar-se da imparcialidade necessária.

A hermenêutica jurídica é aliada poderosa do julgador porque se encarrega de auxiliar na interpretação de textos jurídicos, reúne métodos e técnicas de modo a revelar o verdadeiro sentido da norma ${ }^{34}$. Interpretar (e aplicar) não é mera subsunção do individual ao conceito geral, é instrumento de concretização de princípios.

Quer-se com isso explicitar que o despertar da realidade baseada em valores escolhidos pela Constituição não desestrutura o Direito, inversamente, o torna mais denso. O primado da ordem jurídica é preservado porque abraça o pressuposto do Estado democrático, reconhece a antecedência de direitos, processos e legitimados para intervir em conflitos de princípios ou de direitos.

Desse modo, vincula-se o Estado Democrático de Direito à realização de direitos fundamentais, evitam-se soluções que se restrinjam ao insondável campo da discricionariedade política e das forças insurgentes que afetam artificialmente as escolhas eficientes do mercado, porquanto capazes de falsear a feição democrática que deve reger os processos que conduzem aos ideais republicanos.

Por outro lado, o que se observa é a existência de crise resultante do abandono da dogmática e metodologia jurídica, o distanciamento da abstração e generalidade que se realizam a partir dos fundamentos explicitados, que passam a ser ocupados com a informalidade e deslegitimação do Direito como instrumento de controle e regulação. Há necessidade de se refundar o contrato social que estrutura

\footnotetext{
${ }^{34}$ COVARRUBIAS, A RIVERA. La hermenéutica jurídica Análisis e interpretación de las Leyes Fiscales en México: aportes para un modelo teórico. Instituto Mexicano de Contadores Públicos, 2011. Disponível em: <http:// vlex.com/vid/hermeneutica-juridica-414907922 > . Acesso em: 09 ago. 2015
} 
toda a sociedade por intermédio da Constituição:

Esta abordagem reforça a conexão do Estado constitucional com os direitos de terceira geração, estabelecendo um novo pacto social, ou um pacto constitucional (Verfassungsvertrag), aos quais se remetem certas posições doutrinárias para proteger alguns dos mais emblemáticos dos direitos de terceira geração. É indicado por isso aqui defendendo a paz, proteger a qualidade de vida e do meio ambiente ou a segurança da liberdade de informação, exigem consenso básico dos cidadãos e autoridades públicas sobre estes assuntos que são considerados essenciais para definir o sistema constitucional inteiro. ${ }^{35}$

Exemplo da insuficiência dos instrumentos formais do direito foi trazida a lume com decisão recente da corte holandesa, ocorrida em junho de 2015, proferida na lide proposta em 20 de novembro de 1993 pela Fundação holandesa Urgenda ${ }^{36}$ contra o Reino dos Países Baixos (Urgenda Foundation $v$. Kingdom of the Netherlands). Como solução o órgão julgador determinou que o Estado holandês promovesse significativa diminuição na emissão de poluentes geradores de alterações climáticas. $\mathrm{O}$ acórdão tem fundamento material na defesa do meio ambiente e sustentabilidade. Da perspectiva teórica, baseia-se no princípio da precaução.

A mesma ordem jurídica, que assegura proteção ao meio ambiente, o converte em veículo para dotar de efetividade a igualdade, liberdade e justiça, valores sociais supremos, conforme estatuído no preâmbulo da Constituição brasileira ${ }^{37}$. Esses valores são descompactados ao longo de todo o corpo da Constituição e se estruturam sob a natureza de direitos fundamentais ao identificarem o conteúdo do patamar civilizatório. A implementação desses direitos requer ação positiva do Estado.

Desse modo, fica evidente que a preocupação ambiental afetou a hermenêutica constitucional, reformulando-a, ela está presente na exigibilidade de estudos de impacto ambiental, mesmo de obras já concluídas, configurandose recurso para a Administração Pública rever atos, decisões e situações jurídicas anteriores, ainda que protegidos, inicialmente, sob o manto do ato jurídico perfeito,

\footnotetext{
${ }^{35}$ LUÑO, A. E. Perez. Las Generaciones de Derechos Humanos. Revista Direitos Emergentes na Sociedade Global, 2013, p. 565.

${ }^{36}$ Disponível em: <http://www.urgenda.nl/en/climate-case/> Acesso em: 10 jul. 2015.

${ }^{37}$ Preâmbulo da CF/88 - Nós, representantes do povo brasileiro, reunidos em Assembléia Nacional Constituinte para instituir um Estado Democrático, destinado a assegurar o exercício dos direitos sociais e individuais, a liberdade, a segurança, o bem-estar, o desenvolvimento, a igualdade e a justiça como valores supremos de uma sociedade fraterna, pluralista e sem preconceitos, fundada na harmonia social e comprometida, na ordem interna e internacional, com a solução pacífica das controvérsias, promulgamos, sob a proteção de Deus, a seguinte CONSTITUIÇÂOO DA REPÚBLICA FEDERATIVA DO BRASIL.
} 
da coisa julgada e do direito adquirido, como assegura o artigo $5^{\circ}$, XXXVI, da Constituição Federal de 1988.

Conforme se verifica, valores estruturantes do direito agora precisam acomodar-se aos limites impostos pelo compromisso de preservar o ambiente natural e seus sistemas, com igual hierarquia e importância. Entre os mecanismos de efetivação do Direito Ambiental há também a inversão do ônus da prova que, nas ações ambientais, incumbiria ao poluidor. Toda a teoria da responsabilização do particular, no desempenho de atividade lícita, passa agora por novo crivo quando sua atividade for potencialmente lesiva ao meio ambiente, conforme fazem notar Belchior e Matias:

A racionalidade jurídica clássica, pautada na segurança e em conceitos engessados, não é suficiente para lidar com a complexidade que permeia a relação da propriedade com o meio ambiente, o que faz a discussão ultrapassar um olhar técnico e meramente dogmático, adquirindo um caráter transdisciplinar ${ }^{38}$.

Ocorre que a expressão do direito ao meio ambiente protegido exige postura ativa, não apenas do Estado, mas de toda a coletividade ${ }^{39}$. A proteção ao meio ambiente submete-se à coordenação dos interesses plurais dentro do Estadonação. Neste formato de Estado, o desenvolvimento humano se revela com dúplice função, é limite e, simultaneamente, vetor para o crescimento econômico; vincula os dois como as faces da mesma moeda, um é o reverso do outro.

Por esse modo, o crescimento econômico se constitui de dimensão que o subordina aos imperativos ambientais. Ao analisar as questões postas sobre crescimento econômico, há que se analisar através do filtro hermenêutico da preservação ambiental, as soluções apresentadas devem ser capazes de atender o dever geracional e desenvolver a dignidade humana. O dever geracional se relaciona a "um direito fundamental ao meio ambiente ecologicamente equilibrado, assim como se pode referir a uma 'ordem ambiental' que completa e condiciona a 'ordem econômica' e que, por topologia, integra-se na 'ordem social'”40

Logo, não há como perceber o direito ao meio ambiente ecologicamente

\footnotetext{
${ }^{38}$ BELCHIOR, Germana Parente Neiva; MATIAS, João Luis Nogueira. Propriedade e meio ambiente: uma relação jurídica complexa. Fortaleza: ESMEC, 2011, p. 2. Disponível em: <www.portais.tjce.jus.br/esmec/wp-content/ uploads/2011/08/artigo-3.pdf> . Acesso em: 08 jun. 2015.

${ }^{39} \mathrm{CF} / 88$ Artigo 225. Todos têm direito ao meio ambiente ecologicamente equilibrado, bem de uso comum do povo e essencial à sadia qualidade de vida, impondo-se ao Poder Público e à coletividade o dever de defendê-lo e preservá- lo para as presentes e futuras gerações.

${ }^{40}$ SAMPAIO, José Adércio Leite. Constituição e Meio Ambiente na Perspectiva do Direito Constitucional Comparado. Princípios de Direito Ambiental na Dimensão Internacional e Comparada. SAMPAIO, José Adércio Leite; WOLD, Chris; NARDY, Afrânio (Org.). Belo Horizonte: Del Rey, 2003, p. 98.
} 
equilibrado sem vinculá-lo às gerações presentes. Ocorre que assegurar a preservação para as gerações futuras não é uma opção, nem tampouco reconhecer direito de quem ainda não existe. A titularidade dessa garantia é da geração presente também, é a expressão da continuidade da espécie, do direito de procriar, de deixar herança.

No esforço de garantir sobrevivência, a preservação ambiental é um conceito não plasmado, carente de conteúdo, ainda em construção porque oscila entre duas ideias ligadas à cultura, desenvolvimento e economia de quem o elabora: identificar as necessidades da geração presente e o que deve ser considerado impacto ambiental, inadmissível.

A hermenêutica é a única forma de conciliar a proposta constitucional sem que as pessoas alcançadas por esse ordenamento possam eximir-se do compromisso geracional e universal de viabilidade biológica da espécie humana. Há, portanto, que se distinguir dimensão temporal e espacial, épocas e espaços distintos ligados pela ponte que atende pelo nome de hermenêutica.

Nesse sentido, a ciência jurídica é demandada a dialogar com fatores em constante transformação, que dizem respeito ao grau de desenvolvimento tecnológico, à relação entre produção e consumo, mas, principalmente, à maneira com que os homens se fazem solidários. A ideologia que se forma em torno das opções geradas pelo desenvolvimento tecnológico e econômico parece desafiar respostas diametralmente opostas quando se deparam com o imperativo preservacionista. A investigação dos motivos do antagonismo contribui para que se chegue à distribuição de encargo equitativa e efetiva entre pessoas e instituições, proporcional e compatível como a capacidade de execução e elaboração de objetivos de cada um.

No que se refere ao grau de desenvolvimento tecnológico, quer-se dizer do reconhecimento da capacidade que a humanidade atingiu de se autodestruir ou de gerar catástrofes instantâneas sem que tenha elaborado antídotos igualmente eficazes na mesma velocidade. Não vão longe os múltiplos exemplos das calamidades que envolvem a manipulação da energia atômica, sequelas que alcançam mais de meio século, ou que condenaram cidades inteiras a deixar de existir. Os limites éticos criados nesse segmento precisam ser considerados pela hermenêutica também como reconhecimento da insuficiência do conhecimento humano para dar conta dos efeitos das novas descobertas e de que modo podem afetar a vida humana.

Hans Jonas ${ }^{41}$ convoca imperativos capazes de lidar com os espaços de ação e

${ }^{41}$ JONAS, Hans. El principio de responsabilidad: ensayo de una ética para la civilización. Barcelona: Herder, 1995. 
poder criados com o desenvolvimento da tecnologia, para que esse agir tecnológico se dê de modo responsável. A ausência, ou o desprezo, aos limites éticos da ciência permitiu que a força motriz do desenvolvimento da civilização contemporânea fosse a busca da supremacia militar e da construção de ordem internacional hegemônica onipotente, com efeitos perversos de transformação aleatórias do homem e da natureza. O binômio desenvolvimento tecnológico e econômico importou no crescimento exponencial da capacidade de exclusão e devastação. As escolhas que a história denuncia demonstram a insuficiência do jurídico para fazer convergir as aptidões angariadas ao longo das gerações para a promoção da fraternidade, em favor de todas as formas de vida. Daí a importância da permeabilidade do Direito para a Ética.

Já no que diz respeito à influência que a produção e o consumo exercem sobre a natureza, o primeiro passo seria destituir da humanidade o sentimento atávico de que o ambiente natural é fonte inesgotável de recursos.

A questão crítica, capaz de transformar as relações entre as nações e dentro do próprio território, é a maneira de percepção do outro como sujeito de direito. Ulrich Beck $^{42}$, a seu modo, chama atenção para esse problema quando revela as fronteiras reais e simbólicas que são construídas para distinguir e apartar, colocar de um lado os eleitos, de outro os excluídos. Com o surgimento da sociedade do risco, o ponto de convergência da solidariedade passa a ser o medo, não existe fronteira que separe os que poderão sofrer os efeitos dos gases de efeito estufa, a degradação da camada de ozônio ou a radiação dos experimentos nucleares. A expressão de Falbo e Keller consegue captar a transição que se opera com o surgimento da sociedade do risco:

Enquanto na sociedade industrial clássica o paradigma era o da "igualdade" na sua mais ampla vertente (da igualdade material à igualdade de oportunidades), na sociedade de risco o paradigma passa a ser o da "segurança". Nesta transitoriedade entre os modelos de sociedade, sustentados por aquilo que Beck reconhece serem evidências fenomênicas verificadas em sua Alemanha, há mudança qualitativa no tipo de explicação de solidariedade social. A solidariedade que antes era fundamentada na "carência" (sociedade industrial) passa agora a encontrar seu fundamento no "medo" (sociedade de risco). E este novo tipo de solidariedade social torna-se uma força política. ${ }^{43}$

Desse modo a hermenêutica se depara com realidade que coloca o direito sob a regência do medo, o que implica modificação nas justificativas para interação

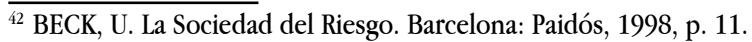

${ }^{43}$ FALBO, R. N.; KELLER, R. J. Sociedade de risco: avanços e limites da teoria de Ulrich Beck / Risk society: advances and limits of Ulrich Beck's theory. Revista Quaestio Iuris, 2015, p. 1999.
} 
entre países e entre as pessoas. Torna-se naturalmente mais difícil a adoção de postura cooperativa quando a precaução e resgate do mal que um possa causar ao outro, ou que já tenha causado, cede lugar à percepção do proveito que a cooperação pode trazer para ambos.

Daí dizer-se que a segurança jurídica desejável - refletida na previsibilidade das decisões, na existência de lei anterior e na responsabilidade - cede lugar a tratamento hermenêutico que se demonstre capaz de apresentar soluções adequadas, mesmo em matéria sobre as quais o homem tem pouca capacidade de influir, como é o caso da natureza.

O desafio consiste em revisitar conceitos que foram estruturantes do direito brasileiro, para refundá-lo, agora sob a imposição ambiental; "certeza e verdade tomam novas dimensões em virtude da necessidade de um gerenciamento preventivo do risco, a própria essência de segurança jurídica, um dos pilares do Estado de Direito, também assume uma nova roupagem" ${ }^{\text {”4 }}$.

De igual modo, há que se relativizar a ideia do direito adquirido, dos atributos inerentes à propriedade e da livre iniciativa. Todos eles, sem deixar de ser plenos, contam agora com outros contornos que o definem, após se depararem com o comando implícito de todo e qualquer ordenamento: fazer uma vida humana melhor. A transformação dos institutos acontece como se dá na natureza como o indivíduo adulto. Após crescer ele modifica a criança que lhe deu origem, sem que isso importe em negar a natureza que o acompanhou em cada época de sua vida, com demandas e necessidades específicas, vividas na plenitude sob os condicionamentos de sua fase. Apesar de se tratar do mesmo indivíduo, graus de consciência diferentes demandam proteção e tratamento igualmente distintos.

A necessidade de preservação ambiental estabelece mais do que valor, mas um telos, objetivo a ser perseguido e alcançado. Para que se chegue ao objetivo traçado é preciso ação, a inércia é incapaz de produzir respostas que a humanidade demanda. O padrão de comportamento que exige proatividade repercute na expectativa e no papel estatal, a ele incumbe regular de modo a assegurar a livre iniciativa e o direito à propriedade sem descuidar da defesa do meio ambiente.

A ausência de ideologia de consenso resulta em pretensão utópica de reunir, em um só ente o que há de melhor dos três modelos - liberal, regulador e social - e

\footnotetext{
${ }^{44}$ BELCHIOR, Germana Parente Neiva; MATIAS, João Luis Nogueira. Propriedade e meio ambiente: uma relação jurídica complexa. Fortaleza: ESMEC, 2011, p. 9. Disponível em: <www.portais.tjce.jus.br/esmec/wp-content/ uploads/2011/08/artigo-3.pdf> . Acesso em: 08 jun. 2015.
} 
sucumbir diante da meta inalcançável de suprir todas as carências humanas.

Para que um Estado democrático seja realmente forte é necessário que sua ordem jurídica seja estável e dotada de legitimidade, ou seja, apoiada na nação. Nas sociedades modernas essa estabilidade e essa legitimidade dependem de uma razoável homogeneidade da sociedade nacional, e de instituições que reflitam o estágio de desenvolvimento e os objetivos dessa sociedade. ${ }^{45}$

Pode-se dizer que a conjuntura que respalda proveito de determinada política pública é mutável, o que não o podem ser são os fundamentos que alicerçam o Estado. Da leitura de Everton Gonçalves ${ }^{46}$ se extrai da realidade atual que se deve buscar, nos momentos de crise, alternativas que viabilizem a reorganização institucional conforme a realidade expressa dentro de contexto social, com as peculiaridades dos seus problemas a exigir soluções imediatas e com conflitos sociais que somente propostas de longo prazo serão capazes de equacionar e a hermenêutica de interpretar.

\section{CONSIDERAÇÕES FINAIS}

A hermenêutica desempenha papel relevante nas questões ambientais, primeiramente por ser capaz de ajustar o tema à importância que detém no atual estágio evolutivo. Contribui para despertar no homem a noção de integrante da natureza e não proprietário. Revela ainda que os ideais liberais econômicos são limitados quando se trata de bem comum, ou de todos, como prefere a Constituição brasileira de 1988 no artigo 225. A intervenção do Estado se legitima exatamente pela tendência de exaustão de recursos comuns quando submetidos ao sistema de ganho de escala, com o aumento de produtividade.

Essa transição se revela em menor parte na edição de novas leis, mas principalmente por intermédio da expressão renovada para interpretar a lei e extrair

\footnotetext{
${ }_{45}$ PEREIRA, Luiz Carlos Bresser. O Conceito Histórico de Desenvolvimento Econômico. 19 dez. 2006. Disponível em: < http://bibliotecadigital.fgv.br/dspace/handle/10438/1973 > . Acesso em: 21 mar. 2015, p. 21.

${ }^{46}$ GONÇALVES, Everton das Neves; STELZER, Joana. Eficiência e direito: pecado ou virtude; uma incursão pela análise econômica do direito. Revista Jurídica. 2012. Disponível em: <http://revista.unicuritiba.edu.br/index. php/RevJur/article/view/412 > . Acesso em: 19 nov. 2014.
} 
delas as questões fundamentais que devem ser consideradas na solução de cada conflito que a norma pretende regular.

A construção jurídica que se fez sobre o meio ambiente o identifica como realidade vital, biológica, indispensável à sobrevivência humana. Se indispensável à vida, o meio ambiente preservado é tomado também como bem jurídico, cuja definição e limite é são desafios postos ao hermeneuta. A preservação da integridade do meio ambiente é direito metaindividual, de terceira geração, que consagra o postulado da solidariedade. Por fim pode-se concluir que é também dever a todos imposto, de tal modo que exige ação positiva do Poder Público e dos indivíduos. Inclusive impõe considerar as gerações futuras e superar o imediatismo que uma lógica puramente econômica de aproveitamento dos recursos naturais pode fazer prevalecer.

A hermenêutica pode fornecer elementos que reduzam o impulso, ou a necessidade, que os intérpretes encontram de servir-se apenas das suas convicções pessoais para a solução dos "casos difíceis", minimizando a irrupção de conflitos intergeracionais e de soberania, já que os efeitos das ações adotadas dentro das fronteiras de um Estado não estão circunscritos aos seus limites territoriais. A capacidade de dotar a argumentação de previsibilidade proporciona avanço no conhecimento interpretativo e dos conceitos que são manejados nas decisões, tais como dignidade da pessoa humana, desenvolvimento humano e crescimento econômico, ou mesmo a defesa do meio ambiente, habilitando-os a alcançar maior grau de revelação e de concretização.

Conforme se viu a hermenêutica clássica preserva influência na interpretação constitucional e ajuda a identificar que a previsão constitucional de defesa do meio ambiente afeta a aplicação das normas e deve ser levada a sério. $O$ enquadramento jurídico e o âmbito de extensão das normas de proteção do ambiente natural trouxeram fundamento de validade da legislação como antes não era considerado.

Por fim, se conclui que a inclusão permanente da preocupação ambiental como critério hermenêutico retira o pesado fardo do julgador de retroceder e elaborar a cada decisão todas as situações em que a lei se supõe insuficiente e que envolvam direitos fundamentais. 


\section{REFERÊNCIAS}

BARACHO JÚNIOR, José Alfredo de Oliveira. Responsabilidade civil por dano ao meio ambiente. Belo Horizonte: Del Rey, 2000.

BARRETO, Ricardo Menna. Do Leito de Procusto à discricionariedade judicial: as implicações do solipsismo filosófico para o direito e sua superação pela hermenêutica jurídica. Prisma Jurídico, v. 10, n. 2, p. 445-470, 2011.

BECK, Ülrich. La Sociedad del Riesgo. Barcelona: Paidós, 1998.

BELCHIOR, Germana Parente Neiva; MATIAS, João Luis Nogueira. Propriedade e meio ambiente: uma relação jurídica complexa. Fortaleza: ESMEC, 2011. Disponível em: <www.portais.tjce.jus.br/esmec/wp-content/uploads/2011/08/ artigo-3.pdf $>$. Acesso em: 08 jun. 2015.

BETTI, Emilio. Teoria geral da interpretação jurídica. São Paulo: Martins Fontes, 2007.

BETTI, Emilio; BLEICHER, J. A hermenêutica como metodologia geral das Geisteswissenschaften. Hermenêutica contemporânea. Lisboa: Edições 70, 1992.

BOBBIO, Norberto. Thomas Hobbes. Tradução M. Escrivá de Romaní. México: Fondo de Cultura Económica, 1992.

BRASIL. Constituição da República Federativa do Brasil: promulgada em 05 de outubro de 1988. Disponível em: < http://www.planalto.gov.br/ccivil_03/ Constituicao/Constituicao.htm>. Acesso em: 08 jun. 2015.

BRASIL. Supremo Tribunal Federal. Ação Direta de Inconstitucionalidade no 2213, Acórdão de Tribunal Pleno. Relator: Min. Celso de Mello. Demandado: Partido dos Trabalhadores - PT/Confederação Nacional dos Trabalhadores na Agricultura - Contag. Brasília, 23 de abril de 2004. Disponível em: <http://vlex.com/vid/-41502842>. Acesso em: 08 jun. 2015.

BRASIL. Supremo Tribunal Federal. Medida Cautelar na Ação Direta de Inconstitucionalidade $\mathrm{n}^{0}$ 3540, Tribunal Pleno. Autor: Presidente da República e 
outros. Demandado: Procurador-Geral da República. Brasília, 03 de fevereiro de 2006. Disponível em: < http://vlex.com/vid/-41548517> Acesso em: 08 jun. 2015.

CALVÃO, Filipa Urbano. Os actos precários e os actos provisórios no Direito Administrativo. Porto: [s.n.], 1998.

CANOTILHO, José Joaquim Gomes. O Princípio da sustentabilidade como Princípio estruturante do Direito Constitucional. Tékhne-Revista de Estudos Politécnicos, 2010. Disponível em: <http://www.scielo.mec.pt/scielo. php?pid $=\$ 1645-99112010000100002 \&$ script $=$ sci_arttext $\&$ tlng $=e n>$. Acesso em: 08 jun. 2015.

CANOTILHO, José Joaquim Gomes. Protecção do Ambiente e Direito de Propriedade. Coimbra: Coimbra, 1995.

CARVALHO, Délton Winter de. Dano ambiental futuro: a responsabilidade civil pelo risco ambiental. São Paulo: Forense Universitária, 2008.

COELHO, André. Introdução à ética do discurso. 2014.

COVARRUBIAS, A RIVERA. La hermenéutica jurídica Análisis e interpretación de las Leyes Fiscales en México: aportes para un modelo teórico. Instituto Mexicano de Contadores Públicos, 2011. Disponível em: <http://vlex.com/vid/ hermeneutica-juridica-414907922 > Acesso em: 09 ago. 2015.

FALBO, Ricardo Nery; KELLER, Rene José. Sociedade de risco: avanços e limites da teoria de Ulrich Beck. Revista Quaestio Iuris, 2015.

FERREIRA FILHO, Manoel Gonçalves. Direitos humanos fundamentais. São Paulo: Saraiva, 1988.

GADAMER, Hans-Georg. Verdade e método I: vol. 7. Trad. Flávio Paulo Meurer. 1997.

GOMES, Ariel Koch. Direito Ambiental: Natureza como um Bem da Humanidade ou como Sujeito de Direitos? Campo Jurídico, v. 1, n. 2, p. 95-124, 2013. 
GOMES, Carla Amado. Risco e modificação do acto autorizativo concretizador de deveres de protecção do ambiente. Faculdade de Direito da Universidade de Lisboa, 2007.

GONÇALVES, Everton das Neves; STELZER, Joana. Eficiência e direito: pecado ou virtude; uma incursão pela análise econômica do direito. Revista Jurídica. 2012. Disponível em: < http://revista.unicuritiba.edu.br/index.php/RevJur/article/ view/412 >. Acesso em: 19 nov. 2014.

HABERMAS, Jürgen. Direito e democracia: entre facticidade e validade. [s.l.]: Tempo brasileiro, 2003.

HEIDEGGER, Martin. Ser e tempo. Petrópolis: Vozes, 1995.

JONAS, Hans. El principio de responsabilidad: ensayo de una ética para la civilización. Barcelona: Herder, 1995.

JOUVENEL, Bertrand de. Essai sur la politique de Rousseau. Berlin-Dahlem: OttoSuhr-Institut, 1965.

KELSEN, Hans. Teoria Pura do Direito. Trad. João Baptista Machado. 7. ed. São Paulo: Martins Fontes, 2006.

LEFF, Enrique. Pensar a complexidade ambiental. In: LEFF, Enrique (Coord.). A com- plexidade ambiental. São Paulo: Cortez, 2003, p. 15-64.

LEITE, José Morato; CANOTILHO, José Gomes. Direito constitucional ambiental brasileiro. 4. ed. São Paulo: Saraiva, 2010. VitalSource Bookshelf Online.

LUÑO, Antonio-Enrique Pérez. Las Generaciones de Derechos Humanos. Revista Direitos Emergentes na Sociedade Global, 2013.

MEDEIROS, Fernanda Luiza Fontoura de. Meio ambiente: direito e dever fundamental. Porto Alegre: Livraria do Advogado, 2004.

PALMER, Richard E. Hermenêutica. Trad. Maria Luísa Ribeiro Ferreira. [s.l.]: Edições, 1999. v.70. 
PEREIRA, Luiz Carlos Bresser. O conceito histórico de desenvolvimento econômico. 19 dez. 2006. Disponível em: < http://bibliotecadigital.fgv.br/dspace/ handle/10438/1973 > . Acesso em: 21 mar. 2015.

PERTENCE, José Paulo Sepúlveda. Atualidade do Pensamento de Kelsen. In: TEIXEIRA, Sálvio de Figueiredo (Coord.). Estudos em Homenagem ao Ministro Adhemar Ferreira Maciel. São Paulo: Saraiva, 2001, p. 463-478.

SAMPAIO, José Adércio Leite; WOLD, Chris; NARDY, Afrânio (Org.). Constituição e Meio Ambiente na Perspectiva do Direito Constitucional Comparado: princípios de direito ambiental na dimensão internacional e comparada. Belo Horizonte: Del Rey, 2003, p. 98.

SARLET, Ingo Wolfgang. Dignidade da pessoa humana e direitos fundamentais na Constituição de 1988. Porto Alegre: Livraria do Advogado, 2001.

SIRVINSKAS, Luís Paulo. Política nacional do meio ambiente (Lei ${ }^{\circ}$ 6.938, de 31 de agosto de 1981). In: MORAES, Rodrigo Jorge; AZEVÊDO, Mariangela Garcia de Lacerda; DELMANTO, Fabio Machado de Almeida (Coord.). As leis federais mais importantes de proteção ao meio ambiente comentadas. Rio de Janeiro: Renovar, 2005, p. 91- 93.

STRECK, Lenio Luiz. Superando os Diversos Tipos de Positivismo: Porque Hermenêutica é Applicatio? Nomos - Revista do Programa de Pós-Graduação em Direito da UFC, Fortaleza, 2014, p. 275-298.

URGENDA FOUNDATION. Landmark climate change lawsuit. Amsterdam, 2015. Disponível em: < http://www.urgenda.nl/en/climate-case > . Acesso em: 10 jul. 2015.

Recebido em: 06 de fevereiro de 2016 Aceito em: 05 de abril de 2016 